Managing tensions between exploitative and exploratory innovation through purchasing function ambidexterity

François Constant ${ }^{1}$, Richard Calvi ${ }^{2}$, Thomas E. Johnsen ${ }^{3}$

${ }^{1}$ Politecnico di Milano School of Management, email: constant.francois@ polimi.it

${ }^{2}$ Savoie University, IAE Savoie Mont-Blanc, email: richard.calvi@univ-smb.fr

${ }^{3}$ Audencia Business School, email: tjohnsen@audencia.com 


\title{
Managing tensions between exploitative and exploratory innovation through purchasing function ambidexterity
}

\begin{abstract}
This paper investigates how companies can manage tensions between exploitative and exploratory innovation by developing an ambidextrous purchasing function. We identify four types of ambidexterity (structural, sequential, contextual and managerial) and discuss how these can be combined to complement each other. We present an indepth case study of a large firm (S Corp), which has implemented an ambidextrous purchasing function to contribute simultaneously to exploitative and exploratory innovation. We observe how the four types of ambidexterity were manifested and applied to balance purchasing's contribution to both exploratory and exploitative innovations. The case study shows how the different types of ambidexterity can be combined to mitigate tensions. Based on our case study findings, we identify a twostage process of developing purchasing ambidexterity, combining the four types of ambidexterity over time. Our findings enrich the understanding of how companies can develop an ambidextrous purchasing function to facilitate purchasing's contribution to exploitative innovation and exploratory innovation.
\end{abstract}

Keywords: Purchasing, Innovation, Ambidexterity, Tensions

\section{Introduction}

To prosper, or even survive, firms must excel at both exploitative and exploratory innovation (Tushman and O'Reilly, 1996). Exploitative innovations are incremental innovations designed to meet the needs of existing customers by developing new products or services that rely predominantly on existing skills that can be mobilized by a company (Jansen et al., 2006; Benner and Tushman, 2003). In contrast, exploratory innovations are radical innovations designed to meet the needs of emerging markets by combining new knowledge from inside or outside the firm (Jansen et al., 2006; Benner and Tushman, 2003).

A long tradition of research in organization theory suggests that, at firm level, pursuing exploration and exploitation goals simultaneously may require structures and actions that are fundamentally at odds, making it difficult to pursue both simultaneously without changing organizational processes (March, 1991; Tushman and O'Reilly, 1996). This dilemma is particularly important in product innovation management as firms need to exploit their existing competencies while trying to avoid dysfunctional rigidity effects by renewing and replacing old competencies with entirely new ones (Atuahene-Gima, 2005; Leonard-Barton 1992). Therefore, creating ambidextrous organizations may facilitate the harmonious development of exploratory and exploitative innovation (Benner and Tushman, 2003; Cantarello et al., 2012).

Organizational ambidexterity refers to the firms' ability to adapt and develop within their environment (Duncan, 1976), and to succeed at both exploration and exploitation (Tushman and O'Reilly, 1996; Raisch and Birkinshaw, 2008). In this context, exploitation activities correspond to the search for familiar, mature, current or proximate knowledge, while exploration activities correspond to the search for unfamiliar, distant and remote knowledge (Ahuja and Lampert, 2001; Rosenkopf and 
Nerkar, 2001; Nerkar, 2003; Atuahene-Gima, 1995). As the benefits of exploration are long term and uncertain, managers tend to put more resources into exploitation than into exploration (March 1991).

Researchers have recently highlighted the need for more investigations into combinations of ambidexterity (Turner et al., 2013), understanding this concept from a multi-level perspective, such as its application to a function (Raisch et al., 2009) or individual level (Rogan and Mors, 2014). For instance, little research exists on how managers orchestrate exploitation and exploration (Turner et al., 2013). Analyzing ambidexterity at just one level is therefore insufficient to embody all antecedents of ambidexterity at a functional level.

In this paper, we argue that investigating ambidexterity within the purchasing function is important because purchasing is increasingly confronted with a dual role (Schiele, 2010), balancing exploitation activities, such as constantly finding ways to save cost, with exploration activities, such as sourcing innovative technology from new supply markets in an open innovation context (Chesbrough, 2003). The concept of purchasing ambidexterity has recently been coined in the literature as "the extent to which a purchasing function simultaneously pursues exploratory and exploitative activities within supply networks" (Gualandris et al., 2018, p. 667). However, balancing exploratory and exploitative activities may be much easier said than done especially in the case of purchasing which is traditionally strongly focused on cost savings. Balancing exploratory and exploitative activities is therefore likely to cause tensions (Andriopoulos and Lewis, 2009). However, despite the relevance of this topic it remains under-studied in the purchasing literature (Blome et al., 2013; Kristal et al., 2010).

Our paper aims to analyze how purchasing ambidexterity can be developed and contribute to managing tensions between exploitative and exploratory innovation. We use a case study research strategy to examine ambidexterity within the purchasing function of a large multi-national company, which has recently made a major organizational change by implementing a "Purchasing \& Innovation" function. This new function oversees the contribution of external resources to exploratory innovations, whereas other purchasing functions remain oriented towards exploitative innovation.

Following this introduction, the paper briefly reviews the literature about ambidexterity as an enabler of innovation performance and defines different types of ambidexterity. We present an initial conceptual framework, explain our case study method and report on the findings from the case study. We discuss the findings in the light of existing research and suggest conceptual developments on purchasing ambidexterity. We conclude by outlining the implications and the limitations of our study and suggest future research directions.

\section{Literature review}

\section{Ambidexterity as an antecedent to innovation}

Ambidexterity explains the firm's capacity to do two different things equally well: manage the short and the long term, manage trade-offs between resource allocations or mitigate tensions between two competing objectives. Ambidexterity through simultaneously exploring and exploiting innovation is key to improve technological innovation performance (He and Wong, 2004). Exploitation involves local search that builds on a firm's existing technological capabilities, providing the firm with advantages in making incremental innovations. In contrast, exploration involves distant 
search for new capabilities, bringing opportunities to the firm in achieving new-to-theworld innovations (Nerkar and Roberts, 2004).

Although achieving high levels of exploration and exploitation simultaneously is the challenge of many organizations, research shows that this is not easily achieved (Brion et al., 2008; Boumgarden et al., 2012; Birkinshaw and Gupta, 2013). Often, organizations "divide their time between conflicting demands for alignment and adaptability" (Gibson and Birkinshaw, 2004, p. 210) and managers fight against organizational routines, invisible forces influencing decisions, calling for new technical skills, market expertise, or external relationships (Lavie and Rosenkopf, 2006). Tensions often arise from combining internal and external technology sourcing (Rothaermel and Alexandre, 2009), and may be resolved at organizational level (Andriopoulos and Lewis, 2009) or at individual level (Mom et al., 2009).

Birkinshaw and Gupta (2013) argue that we need more insights into managerial capabilities to understand how ambidexterity is achieved: "We know some organizations are more ambidextrous than others, but for this insight to be valuable we have to take a more detailed look at the way they make their decisions, who gets involved in those decisions, and how those decisions are implemented" (Birkinshaw and Gupta, 2013, p. 293). This view is shared by Turner et al. (2013) who suggest that ambidexterity reflects a capability of a managerial activity (Turner et al., 2013).

\section{Different types of ambidexterity}

We can distinguish between four types of ambidextrous organizations, differing in the way they shape the organization and operationalize exploration and exploitation activities. The most common distinction is structural ambidexterity versus contextual ambidexterity (Bonesso et al., 2014), but literature also identifies two other types: sequential ambidexterity and managerial ambidexterity (Mom et al., 2009).

\begin{tabular}{|c|c|c|c|}
\hline $\begin{array}{c}\text { Structural } \\
\text { ambidexterity }\end{array}$ & $\begin{array}{c}\text { Contextual } \\
\text { ambidexterity }\end{array}$ & $\begin{array}{c}\text { Sequential } \\
\text { ambidexterity }\end{array}$ & $\begin{array}{c}\text { Managerial } \\
\text { ambidexterity }\end{array}$ \\
\hline \multicolumn{1}{|c|}{} & $\begin{array}{l}\text { Exploration } \\
\text { Exploitation }\end{array}$ & & Exploration \\
\hline Exploitation & & & Exploitation \\
\hline
\end{tabular}

Figure 1: Four types of ambidexterity (Source: Authors)

Structural ambidexterity: Early research on ambidexterity suggested that firms develop two distinct and autonomous organizational units: one dealing with exploration and another with exploitation (Tushman and O'Reilly 1996; Boumgarden et al., 2012). One unit enables the efficient execution of exploitation routines whereas another unit focuses on the execution of non-routine tasks such as exploration and innovation (Raisch and Birkinshaw, 2008). Tushman and O'Reilly (1997) argue that a structural separation between exploration and exploitation activities is key to a successful ambidextrous organization. The main argument in favour of a differentiated organization is that exploration and exploitation tasks are hardly compatible: trying to balance them within one single unit is impossible (Christensen, 1997; Bower and Christensen, 1996) or might create strategic tensions (March, 1991). Separating exploiting and exploring activities allows organizations to develop incremental changes in exploitative units and radical changes in exploratory units (Tushman and O'Reilly, 1996). 
Contextual ambidexterity: Contextual ambidexterity implies that the same people combine exploration and exploitation activities so that both are coexisting instead of being mutually exclusive (Turner et al. 2013). In the last decade, studies of ambidexterity predominantly concluded that organizations tackling exploitation and exploration simultaneously are more successful than others (Lavie et al, 2010). For instance, Birkinshaw and Gupta (2013) argue that if an organization put in place dual structures to deal with exploitation and exploration, then "there is no unit of the organization that does only one thing" (p. 294). However, Raisch et al (2009, p. 687) point out the difficulty of individuals managing exploratory and exploitative tasks simultaneously: "Because the need for exploitation and exploration can vary across initiatives as well as over time, managing the differentiation-integration tensions is likely to be an important dynamic capability for creating and sustaining organizational ambidexterity." The success of this type of organization implies the creation of a supportive context that stimulates individuals to simultaneously manage ambidextrous trade-offs. This context consists of systems, processes or incentives which encourage individuals to optimally allocate their workload to exploitation or exploration (Gibson and Birkinshaw, 2004). Thus, the focus is on individuals rather than organizations, functions or projects (O'Reilly and Tushman, 2013).

Sequential ambidexterity: Exploitation and exploration are sequenced over time and constitute a natural cycle (Rothaermel and Deeds, 2004). Due to constant change of environmental conditions or strategies, firms need to adapt their structures and processes, alternating longer periods with a main focus on exploitation with those of exploration (Raisch and Birkinshaw, 2008; O'Reilly and Tushman, 2013). Keeping one single formal unit and making it regularly switching from exploration to exploitation is easier than adapting the culture and informal organization (Nickerson and Zenger, 2002; Boumgarden et al., 2012). The drawback is that the members of such an organization alternate longer periods of exploitation with shorter periods of exploration and are more likely allocating less focus on exploratory needs (Gupta et al., 2006). Tushman and O'Reilly (1996) suggest that this type of organization is less effective in a context of rapid change.

Managerial ambidexterity: Aggregating various fragments of the literature, Mom et al (2009, p. 812) define managerial ambidexterity as a "manager's behavioural orientation toward combining exploration and exploitation related activities within a certain period of time". In the three previous types of ambidexterity, organizational tensions are due to trade-offs occurring between exploration and exploitation activities. However, managers can also exhibit personal ambidexterity and behave ambidextrously, by resolving tradeoffs at the management level (Raisch et al, 2009, Mom et al., 2009). For instance, managers can build strong links between exploratory and exploitative units to foster complementarities and to reach a balance in execution (Boumgarden et al., 2012; Raisch et al., 2009). Linkages between both are ensured by a set of routines and directives and enhanced by resource sharing, coordination and managerial control systems (Raisch et al, 2009). Senior managers support the implementation of sequential, structural and contextual ambidexterity (Raisch and Birkinshaw, 2008). Birkinshaw and Gupta (2013) argue that managerial capability is central to the contextual ambidexterity perspective, whereas O'Reilly and Tushman (2011) suggest that management controls and culture can support workers to combine contradictory goals within one unit, such as efficiency and control versus creativity. Managerial ambidexterity connects to the fundamental integration mechanisms identified a long time ago by Lawrence and Lorsch (1967). They argue that the more an organization becomes complex due to environmental evolutions, the more it needs to differentiate its structure (structural and sequential 
ambidexterity) and the less effective the coordination between actors. For this type of organization, they advocate the development of integrator managers who are able to act as facilitators between the different parts of the organization. Although managerial ambidexterity and contextual ambidexterity are closely related, there is one clear difference between these: contextual ambidexterity implies that individual employees combine exploration and exploitation themselves, whereas managerial ambidexterity implies that managers choose and allocate resources among exploration and exploitations tasks through integration mechanisms and connections to other organizational members and orchestration of activities.

In sum, we identify four types of ambidexterity in the literature which support the understanding of organizational ambidexterity. We assume that these are not fully exclusive but complementary and scalable over time. In the following we briefly discuss how these may apply to the purchasing field.

\section{Purchasing ambidexterity}

Gualandris et al. (2018) define purchasing ambidexterity as "a balance dimension and a combined dimension between exploration and exploitation activities". This balance is emphasized through the need to reconcile exploitative innovations and exploratory innovations through purchasing operations (Chanal and Mothe, 2005).

On the one hand, contribution of the purchasing function to exploitative innovation has received extensive interest under the banner of purchasing involvement in new product development (NPD) (Wynstra et al., 2003; Van Echtelt et al., 2008, Schiele, 2010). This occurs mainly in a project context when the company is looking for external support in order to design new products or services based on existing technological capabilities. Purchasing can take the lead in managing collaboration with existing key suppliers and securing their early involvement in the NPD process (e.g. Johnsen, 2009; Patrucco et al, 2017).

On the other hand, purchasing may contribute to exploratory innovation (Narasimhan and Narayanan, 2013) through searching for new and distant capabilities that bring opportunities to the firm in achieving more radical innovations (Nerkar and Roberts, 2004). Exploratory innovation is typically characterized by high technological uncertainty (Melander and Lakemond, 2014; Narasimhan and Narayanan, 2013), higher risks (O'Connor and Rice, 2013) and the need of new capabilities (Slater et al., 2014).

The balance dimension considers the extent to which purchasing balances the magnitudes of exploration and exploitation on a relative basis. The combined dimension considers "the extent to which purchasing advances the combined magnitudes of exploration and exploitation." (Gualandris et al., 2018, p. 667). Thus, the purchasing function can be considered as ambidextrous if it is able to equally contribute to exploration and exploitation mechanisms of the firm and at the same time achieve and maintain a high level of performance in exploratory and exploitative activities.

Different types of ambidexterity can be found in the purchasing literature, although they are rarely named as such. Structural ambidexterity in purchasing can be recognized in publications that investigate organizational structures, suggesting for instance that a dedicated scouting unit must be distinct from the strategic unit (Mikkelsen and Johnsen, 2018; Luzzini and Ronchi, 2011). Schiele's (2010) "dual role" of purchasing refers to contextual ambidexterity, as his suggestion is that purchasing works simultaneously on cost reductions and product innovation. Sequential ambidexterity in purchasing has roots in research investigating the purchasing process and its distinct phases among which exploration is key (Linder et al., 2003; Legenvre and Gualandris, 2018; 
Servajean-Hilst and Calvi, 2018). Last, managerial ambidexterity in purchasing can be recognized when it comes to defining a purchasing manager's role in solving organizational tensions (Giunipero and Pearcy, 2000).

\section{An initial conceptual framework}

We aim to better understand how purchasing is organized to combine exploration and exploitation activities in the innovation process. Systematic literature reviews, such as Turner et al. (2013), have emphasized the need for more research to investigate ambidexterity across various levels of analysis, namely organization, group and individual, or a combination of these levels.

Several researchers further suggest that the consideration of various levels of analysis, such as alliance, inter-organizational, organizational, business units, projects, function, or individual level, requires the study of different types of ambidexterity (Raisch et al., 2009; Birkinshaw and Gupta, 2013; O'Reilly and Tushman, 2013; Turner et al., 2013). As shown in Table 1, studying structural ambidexterity focuses predominantly on the organizational level, whereas contextual ambidexterity can be better examined at the functional or the individual levels. 
Table 1: Defining four types of ambidexterity (Source: Authors)
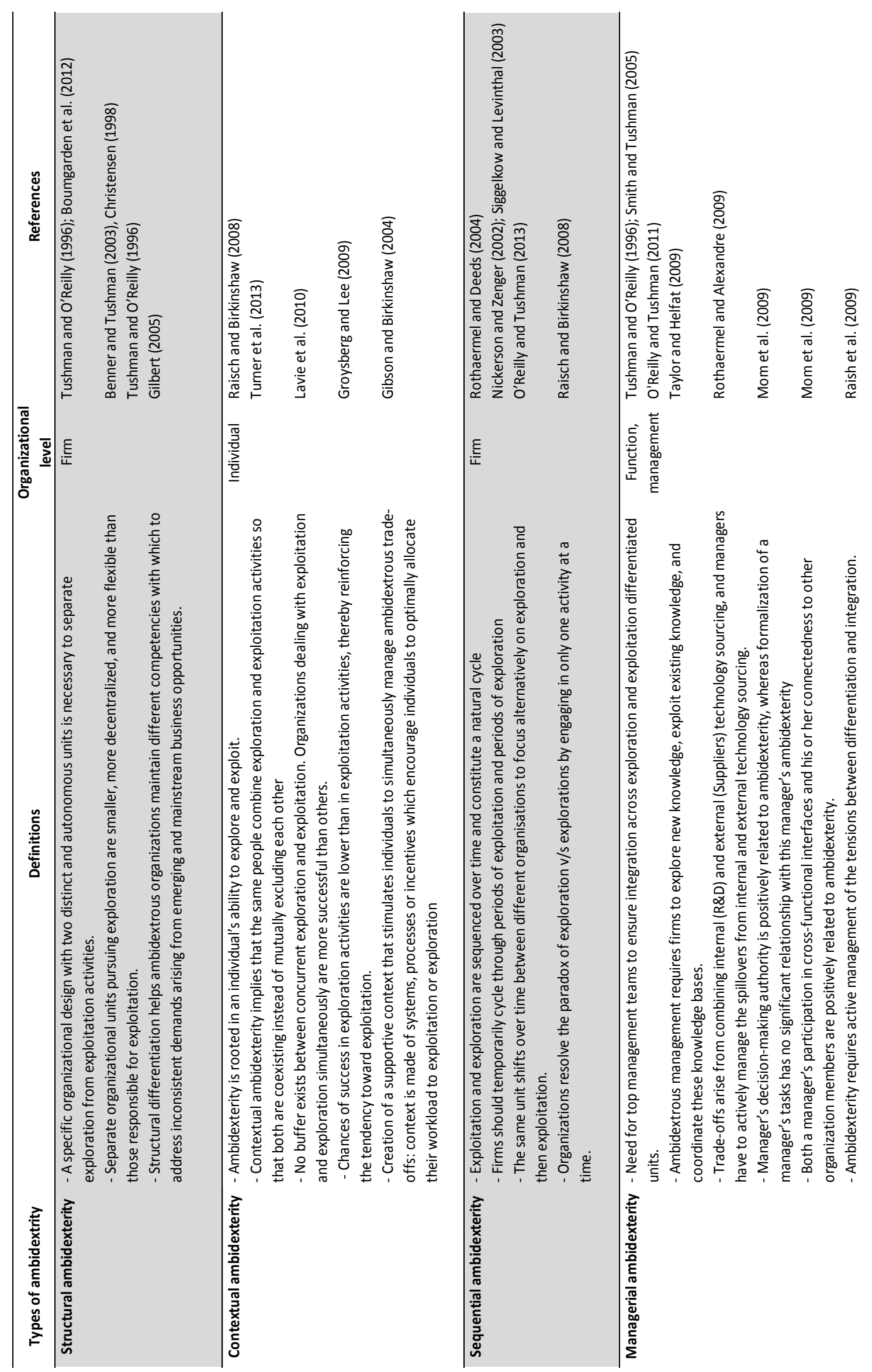
Raisch and Birkinshaw (2008, pp. 396-397) suggest investigating multiple levels of analysis because "choices about how to resolve the tension at one level of analysis are often resolved at the next level down." Other researchers have suggested that studying combinations of different types of ambidexterity is more appropriate at a functional level (Raisch et al. 2009; Andriopoulos and Lewis, 2010). Thus, examining all four types of ambidexterity makes sense when aiming to investigate purchasing ambidexterity and how it combines the four types of ambidexterity defined as the mode of balancing. Thus, our first research question is:

\section{RQ1: How are different types of purchasing ambidexterity manifested?}

Assuming purchasing ambidexterity contains a mix of different types of ambidexterity raises the question of combining different types to create complementarities but this can also cause tensions (Andriopoulos and Lewis, 2009). These tensions stem from inherent trade-offs between exploration and exploitation (March, 1991), which happen when managing businesses with two different dominant logics (Prahalad and Bettis, 1986; Tripsas \& Gavetti, 2000).

Smith and Tushman (2005) report that exploitation and exploration create overarching demands and nested tensions within the firm. Firms face multiple innovation tensions such as conflicts between outside-inside, new-old, determined-emergent, and freedomresponsibility (Dougherty and Hardy, 1996). "Innovation tensions also may foster traps, vicious cycles that stem from increasingly one-sided focus on either exploitation or exploration" (Andriopoulos and Lewis, 2009, p.697). Levinthal and March (1993) identify goal conflict at the management level due to the need to allocate sequentially divergent goals. Managers need to fight against organizational routines and invisible forces influencing decisions and are forced to buffer exploration from exploitation or to choose either departmentalization or sequential goal attention (Lavie et al., 2010).

In the purchasing literature some papers identify typical trade-offs, such as long versus short term, low cost versus better quality (Monczka et al., 2015) or environmental protection versus cost performance (Esfahbodi et al, 2016). In technology sourcing, tensions can arise from combining internal (R\&D) and external (suppliers) technology sourcing, when managers have to actively manage the spill-overs from these (Rothaermel and Alexandre, 2009). Little research has investigated how tensions can be solved at functional level (Raisch et al., 2009; Andriopoulos and Lewis, 2009). Birkinshaw and Gupta (2013) suggest that we need more insights into managerial capabilities to mitigate the impact of these tensions and to understand how ambidexterity is achieved. Thus, our second research question is:

RQ2: What tensions emerge from the need to balance exploratory and exploitative innovations within the purchasing function?

Balancing exploitation and exploration does not reflect a mediocre split or foggy compromise but means excelling at both exploitation and exploration (Atuahene-Gima 2005). However, little agreement is found in the literature on how organizations achieve such balance (Adler et al., 2009). There are various approaches to mitigating tensions, typically divided into two dichotomous streams of research: one fostering differentiation tactics, the other one advocating integration mechanisms (Andriopoulos and Lewis, 2009). However, these studies often focus on one type of ambidexterity in isolation. 
We argue that interactions between the four types of ambidexterity can be also investigated using the lens of complementarities (Cao et al., 2009). Complementarities represent the way organizations achieve a combination of various types of ambidexterity to successfully balance exploration and exploitation. Tensions are not only resolved through one type of ambidexterity, but also through interactions among these. In the purchasing literature, Eriksson (2013) investigated project-based organizations and procurement, arguing that structural and sequential separation of exploration and exploitation activities are not easy to reach without strong integration mechanisms: "cooperative procurement procedures can serve as a basis for facilitating both exploration and exploitation of knowledge and technologies in construction projects" (p. 333). Hence, our third research question is:

RQ3: How are the different types of purchasing ambidexterity combined to reduce tensions between exploratory and exploitative innovation?

Our initial conceptual model shows purchasing involvement simultaneously in exploratory and exploitative innovation and the tensions, which may occur between these two activities: reconciling tensions is a necessary condition for achieving purchasing ambidexterity (Lavie et al., 2010). In turn, balancing the four types of ambidexterity is required to ensure successful purchasing function ambidexterity. Purchasing function ambidexterity can ultimately facilitate purchasing's function contribution to innovation (Legenvre and Gualandris, 2018).

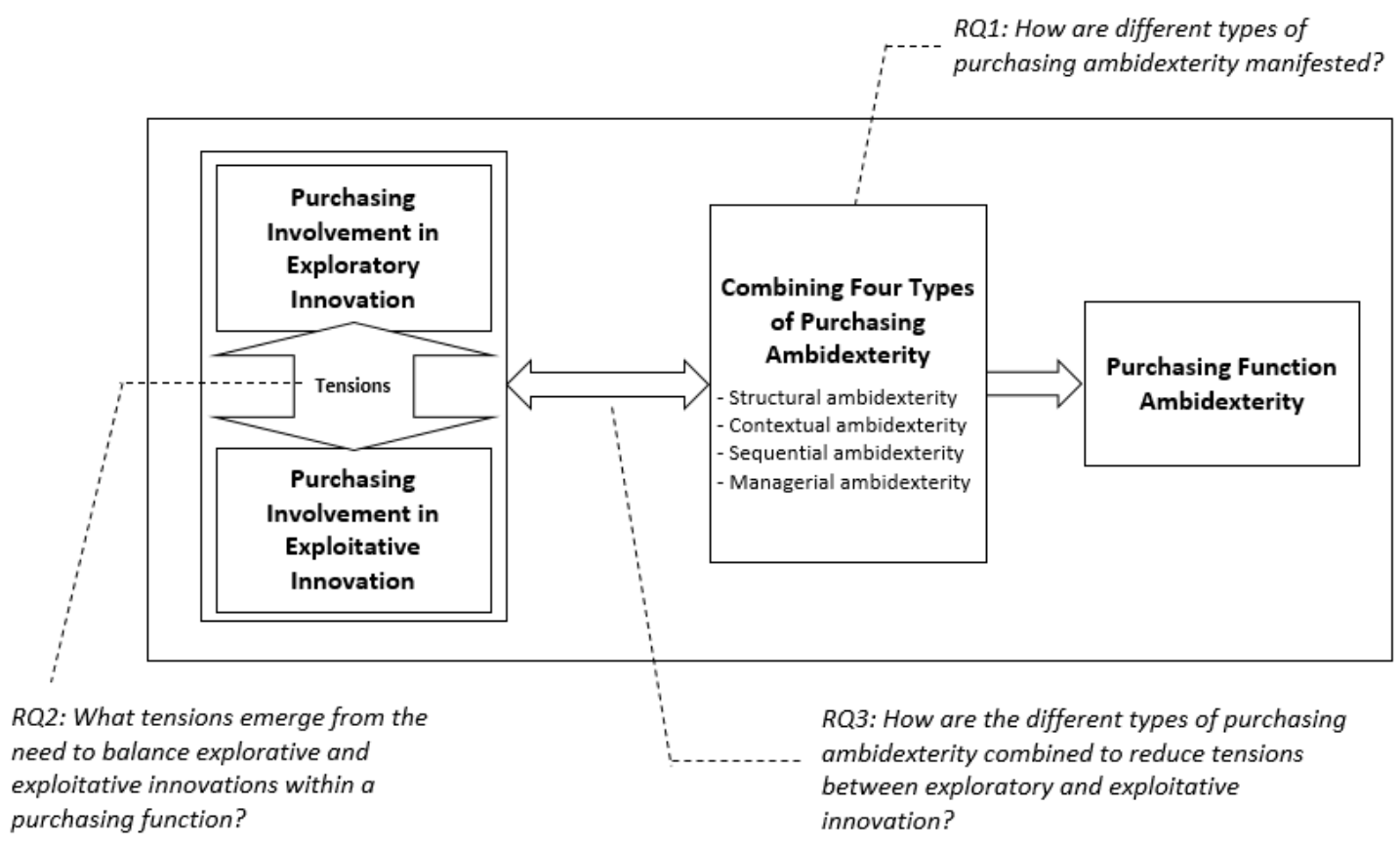

Fig 2: Initial conceptual framework (Source: Authors).

\section{Research method}

Investigating ambidexterity in purchasing requires understanding of multiple interactions - formal and informal - at multiple organizational levels. Therefore, we 
adopted an in-depth case study approach that would allow us to gain rich insights based on collection of data from different functions that interact with purchasing in innovation processes. In this way we were able to "capture the dynamics of a studied phenomenon and provide a multidimensional view of the situation in a specific context" (Järvensivu and Törnroos, 2009, p. 100). Our aim was not to test any pre-existing theory but to elaborate (Ketokivi and Choi, 2014) emerging theory on ambidexterity within purchasing. Thus, we formulated open research questions and an initial conceptual framework based on the literature and aimed to refine this framework based on the case study analysis.

We focused on a single case study because we saw it as essential to gain in-depth insights into the workings within an organization and to really understand the context in which it operates. Our ambition was not to aim for generalization but instead to develop a "force of example" (Flyvbjerg, 2006). We explain this further in the following section.

\section{Case selection}

We searched for what would constitute an exemplar case: "Exemplars are organizations that are well ahead of their industry" (Pagell and Wu, 2009, p40). The case needed to be an exemplar (Dubois and Araujo 2007) of ambidexterity in purchasing, renowned for its excellence in exploitative and exploratory innovation within its market. We identified three key requirements for the company. First, the company's purchasing functions' contribution to innovation should occur in an obvious manner and be "transparently observable" (Pettigrew, 1992). We set out to find a company that had developed an ambidextrous purchasing organization with the purpose of enabling purchasing to contribute to innovation: this was our casing (Raging (1992). Second, the nature of the company should be innovation intensive, demonstrated by a strong emphasize on innovation at every level of the organization, and a commitment to innovation stated in the corporate strategy. Last, this company should have built a purchasing organization sufficiently large and mature to show complex interactions with other departments.

We followed the advice of Raisch and Birkinshaw (2008) who suggest that understanding trade-offs and tensions occurring at a functional level can be better understood while considering the organization level. Therefore, we decided on the company as our unit of analysis in order to better understand ambidexterity at a functional level i.e. purchasing within the context of other internal functions.

We selected a large French manufacturing company, referred to as $S$ Corp: an international leader in connected solutions for building, infrastructures and industry. At a corporate level, the S Corp culture is oriented to long-term views where innovation is a priority. We examined practices already implemented in this firm, across its three business sub-units. S Corp meets the selection criteria in different ways: it shows a record profitability (best ever net income of $€ 2.3 \mathrm{bn}$ in 2018) and belongs to the top-20 innovative French companies in 2018 (measured by the number of patents deposited). Also, based on one author's experience with this company, we knew that S Corp started to involve purchasing into the innovation process over 20 years ago and created a purchasing innovation function less than 10 years after. S Corp belongs to a think tank of five French companies sharing best practices on the subject. We used this as a marker of an exemplar case (Barratt et al., 2011). Furthermore, an initial meeting with a purchasing director confirmed this impression of exemplarity and we therefore decided to proceed with this case.

\section{Data collection:}


We sought to capture different perceptions and meanings in order to understand the dynamics within the company and between different departments. For example, we expected purchasing to believe that it could contribute to innovation but $R \& D$ to be more sceptical of purchasing's contribution. Therefore, we saw it as essential to obtain the views of different departments within the firm as well as both strategic and operational levels. Thus, we interviewed 18 people within Purchasing among which Purchasing \& Innovation, R\&D and R\&I (Research \& Development is more focused on exploitative innovations, whereas Research \& Innovation is a technical department working in advanced phases on exploratory innovations) and Business Development.

Table 2: Interviewees' profiles

\begin{tabular}{|c|c|c|c|c|c|c|}
\hline & $\begin{array}{l}\text { Purchasing } \\
\text { (senior level) }\end{array}$ & $\begin{array}{l}\text { Purchasing } \\
\text { (Operations) }\end{array}$ & $\begin{array}{c}\text { Purchasing \& } \\
\text { Innovation (P\&I) }\end{array}$ & $R \& D$ or $R \& \mid$ & Business devpt & TOTAL \\
\hline & S Corp & S Corp & S Corp & S Corp & S Corp & S Corp \\
\hline $\begin{array}{l}\text { Interviews } \\
\text { (recorded) }\end{array}$ & $2(2)$ & $6(2)$ & $6(6)$ & $3(1)$ & $1(1)$ & 18 \\
\hline $\begin{array}{l}\text { Interview } \\
\text { dates }\end{array}$ & $\begin{array}{l}08 / 12 / 2017 \\
23 / 02 / 2018\end{array}$ & \begin{tabular}{l|}
$15 / 12 / 2017$ \\
$18 / 12 / 2017$ \\
$18 / 12 / 2017$ \\
$26 / 01 / 2018$ \\
$07 / 02 / 2018$ \\
$08 / 02 / 2018$
\end{tabular} & $\begin{array}{l}06 / 10 / 2017 \\
19 / 10 / 2017 \\
09 / 11 / 2017 \\
18 / 01 / 2018 \\
19 / 01 / 2018 \\
23 / 01 / 2018\end{array}$ & $\begin{array}{l}22 / 01 / 2018 \\
24 / 01 / 2018 \\
25 / 01 / 2018\end{array}$ & $10 / 01 / 2018$ & $\begin{array}{c}18 \\
\text { GRAND TOTAL = } \\
\text { interviews }\end{array}$ \\
\hline $\begin{array}{c}\text { Total interview } \\
\text { time }\end{array}$ & $1 \mathrm{~h} 30$ & $10 \mathrm{~h} 48$ & $11 \mathrm{~h} 24$ & $4 \mathrm{~h} 33$ & $1 \mathrm{~h} 39$ & \\
\hline
\end{tabular}

We followed an active interviewing methodology which was treated as a social experience (Holstein and Gubrium, 2004) in a sense that the creation of knowledge is not only one way from the interviewee down to the interviewer. During the discussions, knowledge has been jointly created by the interviewer and the interviewee, because the interviewer directed the interviewee towards the closest answers to the topic. The interviews were semi-structured using an interview guide, but keeping the scope broad, and focusing on processes and events (Easterby-Smith et al., 1991). Thus, consistent with our focus on theory elaboration, we did not seek to operationalize the theoretical constructs and develop pre-determined measures for each of these, but instead asked open-ended questions that allowed interviewees to discuss freely around broad themes.

We asked questions covering three levels within the firm: firm level (organization), functional level (department) and individual level. We sought to ensure that all interviewee voices were considered in the result to keep the research "sufficiently authentic" as defined by Guba and Lincoln (2005): "isomorphic to some reality, trustworthy, related to the way others construct their social worlds" (p. 205). Adopting this view, we sought to understand interviewees' perspectives on the basis of their context, to get as close to an accurate picture of the organization as possible.

\section{Data analysis}

Based on recordings of the interviews we wrote full transcriptions of about $70 \%$ of the interviews; the remaining 30\% were not recorded typically because interviewees were uncomfortable with being recorded so we relied instead on detailed notes. The coding of interview data as captured in the transcripts and/or notes followed the process described by DeCuir-Gunby et al. (2011) to assign "units of meaning to the descriptive or inferential information compiled during a study" (Miles and Huberman, 1994, p56).

The first step of the coding process was to identify evidence of theory-driven codes, including the four types of ambidexterity, the tensions induced by balancing exploration and exploitation and the means to mitigate these. The second step aimed at revisiting theory-driven codes in view of the empirical data. Finally, the third step was to identify 
commonalities and differences across the various interviewees' perspectives. These were organized into a role-ordered matrix, following Miles and Huberman (1994). As shown in Table 3, we grouped the findings from the interviews into groups of interviewees that represented different functions (e.g. departments) within the company because these typically shared the same views. Each column in Table 3 therefore shows our summary of the shared perceptions within each function and thus the differing perceptions across the columns i.e. functions.

\section{Research validity}

Our aim was to investigate and seek to explain a phenomenon in its specific context. The risk of relying on only one case was mitigated through interviewing "a broad spectrum of people with regard to their roles within the company and their experiences" (Dubois and Araujo, 2007, p. 175), to increase the deepness of the observations, and to give multiple angles of perceptions. We also sent reports back to interviewees to gain their confirmation and clarifications in order to correct any misinterpretations. A dialogue between the authors was held in order to maximize mutual understanding and exhaustiveness of each theme (Weber, 1990), benefitting from one author's previous experience of the company.

\section{Findings}

\subsection{S Corp: an innovative company}

S Corp is a company having a global turnover of about $€ 20$ billion with about 150000 employees worldwide (data 2018). Purchasing spend counts for about $50 \%$ of the turnover and is considered as a major contributor of firm's technical and economic performance. Purchasing department has about 1800 employees, traditionally organized in a matrix involving category buyers, project buyers, and serial buyers (called purchasing operations). The firm practices supplier involvement in new product development as a standard. The expenditure is concentrated not only of manufactured components but also raw materials and services. The purchasing strategy is oriented towards supply base rationalization, and emphasizes the increasing spend on suppliers belonging to the new economy, targeting $75 \%$ of new economy suppliers in 2020 ; new economy suppliers refers to suppliers that drive innovations through developments in software, electronic equipment and associated services.

S Corp has a long history of being innovative, driven by technological development. S Corp invests about $6 \%$ of its turn-over in R\&D and owns a 30.000-sqm R\&D in France. To date, S Corp has invested in 25 start-ups in Europe and USA, with whom the group has developed partnerships to detect innovative solutions at an early stage, and to enable their assessment and eventual integration within the company. S Corp targets three main areas of innovations: disruptive technologies (micro-electronics, nanotechnology, intelligent materials and opto-electronics), emerging technologies (mobile communications, micro-electricity generation, sensors) and new services, software and network applications (energy, industry).

The Research \& Development (R\&D) function has traditionally pursued an technologypush strategy. R\&D designed innovations internally and pushed these to the market in the hope of a technological advantage. However, the last decade, S Corp has moved from its technology-push towards a market-pull model; innovations identified within the customer base through what S Corp calls 'customer pain point': 
"We are not in a context where the needs are created and pushed to the market, but we are in a context where marketing creates the needs, once they have identified a customer pain, calling for an action to mitigate it through an innovation" (Purchasing Senior level)

S Corp innovations span the spectrum of incremental and radical innovations according to market and technological uncertainties. One example of a recent innovation is in the field of intelligent public lighting. The business development department identified a 'customer pain', which consisted in reducing electricity consumption in the streets. The customer (a large city) wanted to have automatic public lighting systems connected with sensors capable of detecting movements in the streets. This technology was already available in the market for other applications, but S Corp's R\&D had limited knowledge about it and could not catch up the development on time. The final solution was supposed to replace the current patented smart lighting management which used consumption management through tiltable LED modules. The business development department therefore requested the Purchasing \& Innovation (P\&I) function to find a solution. P\&I had already identified a start-up that had developed an innovative product available as 'turnkey', which used waterproof motion sensors to increase the lumen intensity for 30 seconds when triggered by movement. S Corp incubated the start-up business and began to buy the modified product from the start-up 12 months later under a shared patent.

Another example of an S Corp innovation concerned connected water management systems (Industrial Internet Of Things - IIOT - applied in connected house systems). Forecasted potential market needs suggested a need for better water resource monitoring and management processes, using connected control platforms to provide better insight into operations, reduce time to invoice, etc. S Corp realized this urgent need to adapt to a fast-changing market, although the potential concrete market benefits were not tangible. During a morning brainstorming involving P\&I and the Advanced Research \& Innovation department $(R \& I)$, both realized that they should work together in order to scout external capabilities. R\&D was out of the scope, bypassed by the direct contact between the R\&I department and the P\&I department. To explore the field, P\&I put together a 10-line project datasheet and posted it on an open innovation web platform. The basic principle was a 'call for competence': who could support S Corp in responding to this urgent need? Subsequently, three offers were pre-selected by the P\&I department and transferred to R\&I department for assessment. One of the three solutions was selected and incubated, involving the use of IoT-ready products, edge control, software suites, and digital services. At the time of data collection for our study, the adoption had not yet been decided due to the major investment required and the high level of market uncertainty. Regardless, the P\&I department did succeed in orchestrating the detection, assessment and absorption of this good opportunities.

These exemplify how once a customer pain point has been identified, internal teams begin to explore ways to respond to this. Considered as a superior source of innovation detection compared with $\mathrm{R} \& \mathrm{D}$, the business development function takes the lead in this process. Involving purchasing in the innovation 'pull' process is a recent change, aiming for purchasing to explore and detect innovations in the supplier market. There is still a strong culture where innovation is viewed as 'designed inside' but this has started to change, as innovations coming from the outside are increasingly considered valuable. According to a senior purchasing executive, purchasing had zero contribution to innovation before 2014 but by $201735 \%$ of innovations sourced externally came through purchasing (the rest came from $R \& D$ ). However, the need to contribute to innovation creates a new challenge for purchasing - to be ambidextrous: 
"The challenge is precisely to balance a more supportive mission where we are still asked to exploit our current resources and to respond to an internal demand, with the challenge to propose suppliers' innovations. It's like killing two birds with one stone" (P\&I)

\subsection{Manifestations of purchasing ambidexterity}

Based on our coding process we describe how S Corp combined the four types of ambidexterity in order to cope with the new innovation context. We report on the manifestations of the different types of ambidexterity, the tensions occurring between exploration and exploitation, and the mechanisms to mitigate these tensions. Table 3 gives an overview of the differing perceptions of these divided into the main interviewee groups.

\section{Structural purchasing ambidexterity}

As in many organizations, S Corp purchasing is involved in NPD projects to scout supply networks to find suppliers capable of manufacturing an innovation designed by R\&D. The traditional purchasing team is involved in NPD and exploitative innovations, managing operations, projects and category sourcing. However, fifteen years ago, $\mathrm{S}$ Corp realized that R\&D and category purchasing inhibited innovation if they were not complemented by another organization including a new purchasing function dedicated to contribute to innovation. Thus, in 2005 S Corp implemented a new function called "Purchasing \& Innovation" (P\&I), structurally separated from the rest of the purchasing organization. S Corp decided that a structural differentiation between traditional purchasing and P\&I was the best way to achieve concrete results in innovation.

The P\&I unit is independent from purchasing operations but still belongs to the purchasing organization and reports to the Chief Purchasing Officer. P\&I's objective is:

“to first understand customers' market needs, then $R \& D$ 's needs and finally match both with the supply network capabilities. Therefore, we have trained our team to talk to $R \& D$ and also to listen to marketing, sales, business units, etc... because we want to pull the knowledge up from the market" $(\mathrm{P} \& \mathrm{I})$

The P\&I team scouts the supply market to detect any innovation which could be valuable for the firm. With only five full time "innovation buyers", P\&I remains small compared to the rest of purchasing department that counts 1800 employees in total. P\&I manages about 50 people inside or outside the purchasing department for an equivalent work load of 12 full-time employees. This unit is focused on exploration, scouting for new opportunities and listening proactively to new customer needs: it is smaller, more decentralized, and more flexible than the core purchasing team. This differentiated structure avoids purchasing having to deal with both exploitative and exploratory activities.

\section{Contextual purchasing ambidexterity}

Contextual ambidexterity can be observed at various individual levels within S Corp purchasing. Firstly, most P\&I buyers are not dedicated full time to innovation exploration but divide their time between exploratory and exploitative activities. Apart from five full time "innovation buyers" the rest of the P\&I community consists of about 50 buyers working part-time on exploration; their task is to balance exploratory and exploitative tasks:

"Of course, they do not dedicate 100\% of their time to exploration because they are also involved into projects development, not innovative programs, but still have the training and background and fundamentals to speak fluently about innovation with suppliers" (P\&I)

Secondly, we can recognize contextual ambidexterity among S Corp Purchasing at the business unit (BU) level. The BUs manage projects, i.e. the development of new 
products, and work closely with the business development function. Project buyers are mainly involved in exploitative innovation and NPD, when innovations are 'translated' into a new product going through project milestones, but they are also tasked with contributing to exploration:

"[Project buyers] contribute mainly to the short-term project development for which time to market is important because we have to push the product to the market as quickly as possible. But we can also leverage on our current suppliers to reduce total cost of our project, leveraging on their innovations. But we have to keep pushing exploring to get real opportunities". (Purchasing operations)

Thirdly, contextual ambidexterity is found at category purchasing level, which is a cross-BU function belonging to purchasing operations. The contextual ambidexterity reflects the fact that each individual is expected to deal with both exploratory and exploitative activities. For instance, category buyers define sourcing strategies and reduce purchasing costs for the company, implying a perfect knowledge of supply market and new technologies. Indirectly, these buyers are also involved in innovation scouting in addition to their daily category management activities, because it helps at achieving their cost reduction objectives:

"Category buyers need to explore and find innovations by their own. Normally, innovation is not our main objective at all. But we count on innovation to improve our supply base cost effectiveness" (Purchasing operations)

Overall, the contribution of the P\&I department is limited in a sense that it does not provide short-term opportunities to operation buyers. P\&I does not provide enough visibility to category buyers because $\mathrm{P} \& \mathrm{I}$ is focused on more radical innovations which need long assimilation and absorption plans, too long in the time frame of a category buyer. So, category buyers need to devote their time not only to transactional activities but also on exploratory activities, like the search for innovations which provide shortterm cost reductions.

\section{Sequential purchasing ambidexterity}

S Corp organizes the innovation process into three phases, in which exploratory activities precede exploitative activities. The first phase corresponds to the search and survey of advanced innovations: S Corp has not yet defined a project and they do not know what they need although they do know that something needs investigating. The second phase involves developing offers and products with a clear time to market and the third phase is the commercialization of offers. These phases are organized sequentially, i.e. one after the other: S Corp's processes reflect this sequence. Purchasing (P\&I) is involved in all three phases although being involved in first phase is a recent development:

"P\&I is involved in the three phases of the innovation process. We are first involved in the detection phase of innovations (phase 1), we push them into development (phase 2) and we support the commercialization of this innovation (Phase 3). This phase 2 is critical and time consuming for us." (P\&I)

When innovations are sourced externally, S Corp P\&I starts exploring both the current and new potential supply base. Once detected, P\&I buyers have to convince internal stakeholders of the potential value of the innovation. If adopted, the innovation is included in the development phase during which the innovation is transformed from a concept into a new product. Commercialization is the ultimate exploitation phase, when P\&I continues to follow end customer feedback. The process alternates longer periods of exploitation with shorter periods of exploration, reflecting a sequential path in which P\&I is deeply involved. This is a sequential ambidexterity process with P\&I balancing exploratory and exploitative activities over time. 


\section{Managerial purchasing ambidexterity}

About fifteen years after the implementation of the new P\&I function (so in 2018), a new position at senior management level was created within the P\&I function to act full-time as 'innovation champion', perceived as an architect of innovation activities between the supply base and S Corp. The term "architect" reflects its coordination role to orchestrate and to provide support to connect supplier innovations with internal stakeholders:

"I have built a community internally and I animate it throughout the whole purchasing organization and possibly also with the other functions. Basically, it's all about creating interfaces with people from technology and marketing, people from open innovation, people from operations, on the innovation topics" (P\&I champion)

The P\&I champion also surveys the supply market and assesses potential innovations. The supply market not only includes the existing supply base, but also new potential partners such as universities, start-ups, clusters, incubators.

"My role is first to detect the innovation within supply base. During the detection phase, I have to assess whether the innovation is relevant and makes sense from a technological and business perspectives." (P\&I champion)

Once the innovation is detected and assessed, P\&I must convince R\&D and other departments of its potential. Several interviewees emphasized that credible leadership skills are a key success factor in the P\&I champion position:

"I need to challenge the adoption, to convince internal stakeholders that this innovation is valuable. Once the decision to adopt the innovation is made, my role is also to support the development and exploitation. I need also to convince the innovation provider to open its doors, because a start-up is often reluctant to disclose its innovation to a large company like us " (P\&I champion)

Complex innovations or relationships with nested suppliers require the need for better orchestration capabilities. Orchestration means facilitating decisions involving multiple stakeholders, enabling the company's agility to move in one direction or another, maintaining a strategic vision of internal and external capabilities.

"I need to coach each member of the community, including the innovation provider, until the commercialization phase, spreading more agile practices. It is like creating interfaces between people and bridging with external capabilities in order to improve the organization efficiency towards innovation." (P\&I champion)

In sum, this champion role to actively resolve the trade-off between exploration and exploitation objectives constantly exists in the day-to-day activities of the purchasing function in $\mathrm{S}$ Corp. This illustrates the role of managerial ambidexterity as a key capability to orchestrate exploratory and exploitative activities.

\subsection{Tensions between exploration and exploitation}

S Corp faces important challenges, such as the insufficiency of internal design capabilities to develop modern solutions, the need for agile offers to address different market positions and even completely new market segments. The complexity and variety of the tensions made it difficult to identify these during the interviews, as they were nested within the firm and interviewees did not disclose tensions spontaneously but were more likely to emphasize their successes. However, when pushed interviewees revealed underlying tensions related to the different forms of ambidexterity. The coding process helped us to identify four main tensions emerging repeatedly during the interviews.

Tensions related to purchasing resource allocation: Buyers involved in exploratory innovation are not dedicated full time to exploratory tasks so are overloaded with daily operational tasks and cannot devote sufficient time to innovation exploration. Some 
buyers spend a small proportion of their time on exploratory activities and judge this as ineffective for capturing innovation opportunities:

"... the best would be to have fully dedicated teams. The reason is that if you are too much involved in daily operational tasks and program development, the priority will be operational or program emergencies. There is a critical involvement to reach, let's say the minimum is $50 \%$ of your time devoted to innovation exploration, the better is full time of course. Today we struggle to spend enough time on exploration phases" (P\&I)

This affects individual planning and efficiency in innovation exploratory activities. Buyers feel frustrated when missing exploration objectives and argue that doing both exploratory and exploitative tasks within a single mission profile is hardly compatible. This reflects tensions created by contextual ambidexterity, as individuals are expected to work simultaneously on exploratory and exploitative tasks within the same function.

Tensions related to purchasing integration to other functions: Tensions also occur between functions. Several interviewees question the creation of a specific purchasing unit focused on technological innovation, which challenges structural ambidexterity itself. Tensions are exacerbated between $R \& D$ and purchasing, because $R \& D$ views purchasing's role as disconnected from technological concerns. R\&D argues that purchasing normally should not concern itself with innovations because they are not experts in technologies. R\&D also finds it hard to accept that an external supplier is capable of doing something better or quicker than they can. Purchasing is sympathetic to this position and understands that this is the result of a long tradition in technology and innovation. But R\&D can be harsh:

\footnotetext{
"Purchasing is supposed to find innovations from their familiar suppliers. But this is rarely efficient, because the buyer who negotiates with a supplier has objectives in mind relating to a contract, a price reduction, or an end-of-year rebate: all these aspects will take the priority towards an open discussion about innovations. So, you can imagine that purchasing shouldn't deal with new technological partners such as start-ups or universities" (R\&D)
}

This illustrates tensions occurring when ambidexterity is implemented by means of a structural differentiation between exploratory and exploitative functions which partitions the purchasing function. When integration is not well managed, other departments perceive this differentiation as surprising, or sometimes irrelevant. In comparison, we observed that P\&I integration with the business development function was particularly strong and even stronger than with the technical functions.

Tensions related to transitions between innovation phases: The consideration of innovation as a sequential process, where exploration precedes exploitation, implies a difficult transition between exploration and exploitation phases. This transition creates coordination tensions which are exacerbated by processes or individual behaviours. Major differences in the nature of activities between exploratory and exploitative tasks call for a radically different time-to-market perspective, customer commitment and return of investment timeframe. Such tensions are supposed to be resolved at a top management level, but this is not facilitated by the differentiated organizational structure. Several interviewees suggested that P\&I needs to convince internal teams to adopt supplier innovations:

"What is difficult in innovation sourcing, is not to find the innovative supplier, the start-up or the partner providing a very high-tech solution, it is that we don't know how to convince internal functions that they should develop this innovation. Compared to innovation detection, convincing people is ten times trickier and creates a lot of tensions" (P\&I).

The sequential split between exploratory and exploitative activities poses numerous problems internally. This reflects sequential ambidexterity and the challenge of managing transition between sequenced phases. 
Tensions related to purchasing skills and processes: Tensions appear within purchasing operations as it struggles to perform exploratory activities. Purchasing operations believes that P\&I receives all the resources, creating a sense of inequality and fight over resources. Moreover, purchasing operations are not equipped with the skills to scout for innovative suppliers and the traditional purchasing processes cause problems.

As in many other firms, purchasing operations used to categorize purchasing needs into commodities, which includes a rigorous supplier selection process. However, this process is perceived by purchasing operations as poorly adapted to sourcing from innovative suppliers. For example, a traditional supplier audit grid is ill-suited to assess the potential success of start-up relationships. By reasoning in categories, purchasing has extensive knowledge of the supply market for one category, but has no understanding of how to source an innovation, a concept or an idea. Lastly, purchasing operations argue that scouting innovative suppliers requires different tools, such as the use of open innovation platforms and purchasing suites. Thus, tensions often occur within the purchasing department, because people feel ill-equipped to accomplish the mission which they have been assigned:

\footnotetext{
"For sourcing innovations or functionalities, purchasing operations is not well equipped. We must change entirely our way of thinking in categories, get trained to new tools: this is a radical change for us" (Purchasing operations)
}

P\&I also point to other tensions as a result of unsuitable purchasing skills and processes. For instance, contracting with a start-up requires intensive discussions about intellectual property and confidentiality terms, which are not needed in contracting terms with a commodity supplier. Consequently, P\&I complains about employees from purchasing operation lacking skills to scout innovations and to develop partnerships with start-ups. P\&I also believes that there is a lack of coordination between the numerous operation buyers working on topics related to innovation and missing processes around common objectives.

\subsection{Combining the four types of ambidexterity}

The case study illustrates not only tensions but also combinations between the four types of ambidexterity. First, structural ambidexterity is combined with sequential ambidexterity within the purchasing function. The structural design of the S Corp organization, divided into two separate units for exploratory and exploitative activities, is viewed as effective by interviewees but only if activities are sequenced over time, i.e. starting from exploratory and finishing with exploitative activities. Most of the purchasing workforce at $\mathrm{S}$ Corp focuses on exploitation, preparing and executing sourcing for NPD or similar exploitative activities. Only a minority of purchasing employees are engaged in exploratory activities. Thus, organizing into two distinct activities over time is viewed as necessary to schedule the tasks and leverage on different skill sets. The necessary corollary is that this requires strong management of the transitions:

"To manage transitions between different phases, we need of a strong coordination at the organizational level and a spread of the workload among purchasing operations." (Senior purchasing)

Second, contextual ambidexterity is combined with managerial ambidexterity. We observed that buyers in the two distinct structures had no strict focus on either exploratory or exploitative activities, but the two structurally separated units maintained a different balance between exploration and exploitation. Thus, many employees are required to be ambidextrous, reflecting contextual ambidexterity at an individual level. $\mathrm{S}$ Corp interviewees see this is feasible because strong coordination mechanisms are 
implemented which stimulate individuals to simultaneously manage ambidextrous trade-offs: systems, processes and incentives encourage individuals to allocate their workload to exploratory or exploitative activities. This happens at the management level, through the position of P\&I "champions" and processes to orchestrate the numerous tasks related to innovation:

"Although there is a separated unit, S Corp needs people involved in both activities to smoothen the transition between innovation phases. But people stress when they're engaged into two different timeframes: short term with operations, long term with innovation. So, management is key to provide a supportive infrastructure and to help buyers to plan their workload." (Senior purchasing)

Third, the findings show that a combination of managerial purchasing ambidexterity and contextual ambidexterity facilitate sequential ambidexterity through the creation of cross-functional contacts and incentives. The four types of purchasing ambidexterity in $S$ Corp are not stand-alone practices but interrelated approaches that together create the purchasing ambidexterity capability. Combining contextual ambidexterity at the individual level and managerial ambidexterity at the function level seems to help S Corp to overcome the tensions that result from having to balance exploration and exploitation activities in two differentiated units (structural ambidexterity) or switching between them (sequential ambidexterity):

"We have implemented mechanisms to integrate P\&I in other decision structures, so that P\&I knows what's happen there but also they facilitates the overall success of our company. Hopefully they mitigate biases created by our dual organization." (VP Purchasing)

Table 3 shows the findings on the four types of ambidexterity organized into manifestations, tensions and mechanisms to reduce tensions. As explained in our data analysis section, the findings from our interviews were divided into groups of interviewees that represented different functions (e.g. departments) within the company because, as we have reported in this section, the different functions typically shared the same views but these were often in stark contrast across functions. In particular, Table 3 shows the differing perceptions of purchasing operations and R\&D and R\&I: PO sees itself as well-placed to contribute to innovation but knows that it lacks legitimacy in the eyes of $R \& D$ and $R \& I$. In contrast, the dominant view within $R \& D$ and $R \& I$ is that purchasing should not be involved in innovation activities and that they struggle to balance their daily purchasing tasks with innovation activities. There are even conflicting views between $R \& D / R \& I$ and $P \& I$ in some areas as the latter is viewed by some $R \& D / R \& I$ interviewees as being overly concerned with cost issues. These differences are often a source of tensions as purchasing and R\&D/R\&I look at each other with suspicion. P\&I then perform both an external bridging role towards suppliers and an internal bridging role between purchasing and $R \& D / R \& I$. 


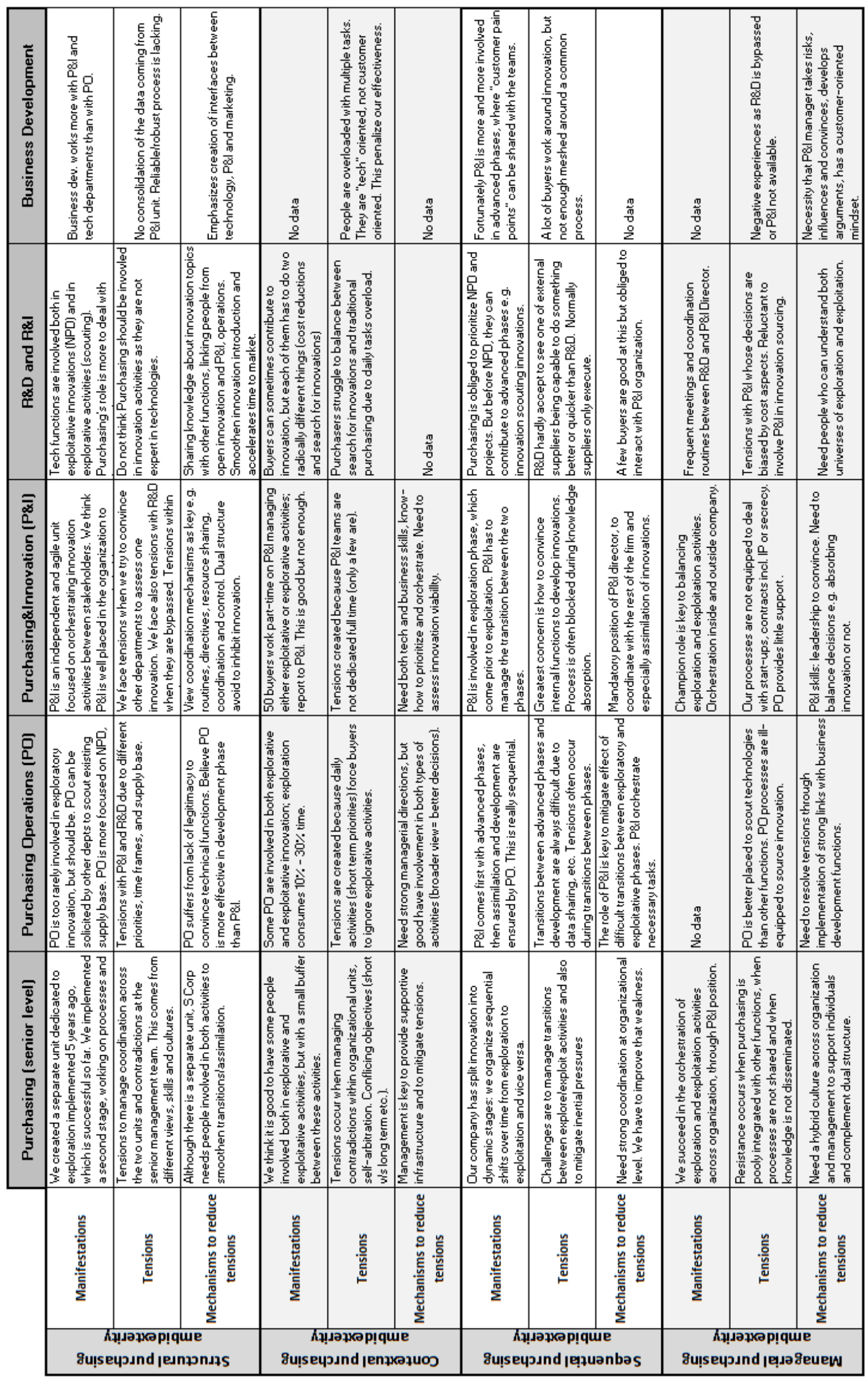

Table 3: Cross-functional perceptions of four types of ambidexterity (Source: Authors). 


\section{Discussion}

Previous researchers outside the purchasing field have studied ambidexterity in different forms. In this section, we present our findings on purchasing ambidexterity in the light of this wider literature. At the same time, we address the three research questions and enlarge the debate by using additional theory grounding.

\subsection{Manifestations of purchasing ambidexterity (RQ1)}

The S Corp case exemplifies structural ambidexterity within the purchasing function where traditional purchasing is focused on daily transactional tasks and P\&I is focused on explorative activities. These are structurally separated so are independent functions with their own routines and objectives. The structural separation has existed for over 15 years, suggesting that $\mathrm{S}$ Corp considers it an effective way to create ambidexterity that enables purchasing to better contribute to innovation.

In addition, we observed that the same employees from project and category purchasing functions alternate between long periods of exploitation and short periods of exploration, illustrating sequential ambidexterity. S Corp's P\&I function first enters the fuzzy front project phase to manage innovation scouting, followed by project and category purchasing functions in the innovation exploitation phase. Innovation exploration takes place before exploitation in a sequential process, although in our case study more employees are involved in innovation exploitation. This complements Brown and Eisenhardt's (1997) conclusions, later confirmed by Gupta et al (2006), that employees in traditional organizations are more familiar with and more focused on exploitation (Gupta et al., 2006). Switching between exploration and exploitation is far easier than changing the culture of the organization (Nickerson and Zenger, 2002; Boumgarden et al., 2012).

Our analysis identifies other manifestations of purchasing ambidexterity. Employees from project and category purchasing are individually involved in both exploration and exploitation tasks, thus indicating contextual ambidexterity. This dual contribution is facilitated by the organizational culture and context: all functions including project and category purchasing are encouraged to adopt creative behaviours in addition to their traditional tasks, through administrative mechanisms such as incentives and rewards. The firm's culture as described by the CEO is captured in its vision to foster innovation, which creates a context that cultivates employees to align their activities with the search for new ideas. Gibson and Birkinshaw (2004) argue that when a supportive organizational context is created, individuals engage in both exploitation-oriented actions (geared toward alignment) and exploration-oriented actions (geared toward adaptability), and this also results in the contextual purchasing ambidexterity found in the $\mathrm{S}$ Corp case.

Finally, our study highlights the existence of managerial ambidexterity. At S Corp, exploratory and exploitative units have cross-functional interfaces such as "champions" who are tasked with facilitating knowledge exchange across units. Champions orchestrate and coordinate innovation activities and are instrumental in making purchasing's contribution to innovation more effective. Such a role has also been described by Maier et al (2017) in a study of a German technology firm which is similar to S Corp. This is also aligned with Gupta and Govindarajan (2000), arguing that "liaison personnel" facilitate transitions between exploration and exploitation. These links represent bridges that are artificially created during meetings, across functional teams, such as between R\&D and purchasing or between marketing and purchasing, during which distinct or complementary knowledge is shared. Cross-functional 
interfaces allow employees from different departments to better understand the challenges faced by other units and to reach a common understanding of objectives and methods.

\subsection{Tensions between exploratory and exploitative innovation ( $R Q 2)$}

As shown in Table 3, the S Corp case demonstrates that inevitable tensions and conflicts occur when purchasing seeks to contribute to both exploratory and exploitative innovation simultaneously. A typical example of a tension is when P\&I detects an innovation outside S Corp's traditional supply base. In such cases, the technical functions $R \& D$ and $R \& I$ are reluctant to consider the opportunities, as they do not originate from within the firm.

S Corp's P\&I function struggles to unravel the difficult balance between exploration and exploitation in the development phase. Nevertheless, S Corp is able to achieve positive results considering the large number of innovations brought into the firm resulting from purchasing exploration. Tensions are partly mitigated as purchasing managers nurture the company with fresh external supplier knowledge. S Corp leaders also succeed in allocating resources between exploration and exploitation, embedding managerial ambidexterity. O'Reilly and Tushman (2013) suggested that the successful achievement of ambidexterity comes from the leaders' ability to manage tensions between exploration and exploitation tasks, which can make organizations more ambidextrous than others (Birkinshaw and Gupta, 2013) and we observe this in S Corp.

Our study enables us to distinguish a set of trade-offs which cause tensions due to various types of ambidexterity. Creating an ambidextrous purchasing organization is a powerful way to enable purchasing to contribute to innovation but our findings demonstrate that this may create serious tensions. We identified four types of tensions: 1) purchasing resource allocation, 2) purchasing integration with $R \& D, 3$ ) transitions between innovation phases, and 4) purchasing skills and processes. At S Corp, these tensions are reduced by a complex set of coordination mechanisms, which we expand on below.

\subsection{Combining different types of purchasing ambidexterity to reduce tensions between} exploration and exploitation (RQ3)

O'Reilly and Tushman (2013) observed a lack of research clarifying how sequential ambidexterity, and more specifically the transition from exploration to exploitation, occurs at the managerial level and how resulting tensions can be solved. We observed how S Corp views this transition as highly sensitive. We also noted how the P\&I function contributes to the transition between the exploratory and exploitative phases by effective assessment of innovations to convince functions, such as R\&D, to pursue these. The S Corp case exemplifies how the combination of managerial purchasing ambidexterity and contextual purchasing ambidexterity at individual levels facilitates sequential ambidexterity through the creation of cross-functional contacts and incentives. These stimuli motivate co-workers and enable the innovation process to proceed to innovation development.

Moreover, the S Corp case shows how the creation of a dedicated function to span purchasing and R\&D - the P\&I function - can be a way to put in place the right skills (Gupta et al., 2006), and that individual knowledge, or a specific process, is necessary to combine or switch between routines of exploration and exploitation. We observed how $S$ Corp's CEO promoted a new culture oriented towards innovation and spread the firm's values and missions to all employees: this helped to orient S Corp's culture towards long-term views with innovation as a priority. This highlights how the creation 
of a supportive context allows individuals to simultaneously handle ambidextrous requirements within the same function and to manage the transitions between the phases of sequential ambidexterity. This is in line with Raisch et al. (2009), who argued that ambidexterity at a function level might support the firm's innovativeness through individual ability to deal simultaneously or sequentially with exploration and exploitation.

Also, we have noted that the P\&I function is closely integrated with the business development and marketing functions: integration takes place through individual behaviour and the networking ability of purchasers that enable them to become aware of customer needs or "pain points". Previous literature on ambidexterity suggests that resources and capabilities are used effectively when people, structures, processes and cultures from different units are merged or integrated (Tushman and O'Reilly, 1996). Integration calls for inter-dependent tasks, specific processes or "functional integration", referring to "intra-firm collaboration and information sharing activities" (Swink and Schoenherr, 2015). Recent research describes functional integration as a bidimensional process, which requires shared information as well as aligned decisions (Gonzalez-Zapatero et al., 2017). These mechanisms enable organizational effectiveness for structurally or sequentially separated exploration and exploitation. The presence of integration mechanisms within S Corp indicates a certain organizational maturity (Jansen et al., 2009). Gonzales-Zapatero et al. (2017) also give insights into the benefits of purchasing integration with marketing, bridging with the idea that integration supports supplier innovation and creative capabilities (Schoenherr et al, 2012). Thus, managerial and contextual purchasing ambidexterity contribute to purchasing integration and consequently facilitate structural and sequential purchasing ambidexterity.

Finally, we observed how the four types of ambidexterity are combined over time. S Corp developed its purchasing ambidextrous structure in two major stages over the past two decades. Structural and sequential ambidexterity were implemented initially under the former CEO's initiative (Stage 1). S Corp added the P\&I structure to its former matrix organization, and shaped innovation development as a sequential process. This was seen as a viable solution for around a decade. Arriving in the early 2010s, the new CEO strengthened this structure by adding new processes, tools and skills (Stage 2). Thus, S Corp completed its ambidextrous organization by improving the supportive context of innovation orchestration through various coordination mechanisms, including the P\&I champion role. These two stages reveal a two-stage vision of ambidexterity development in purchasing, reflecting S Corp's way of combining the four types of ambidexterity over time, but there is no literature about the longitudinal development of organizational ambidexterity. We can represent the two stages and the complementarities as the following (Figure 3): 


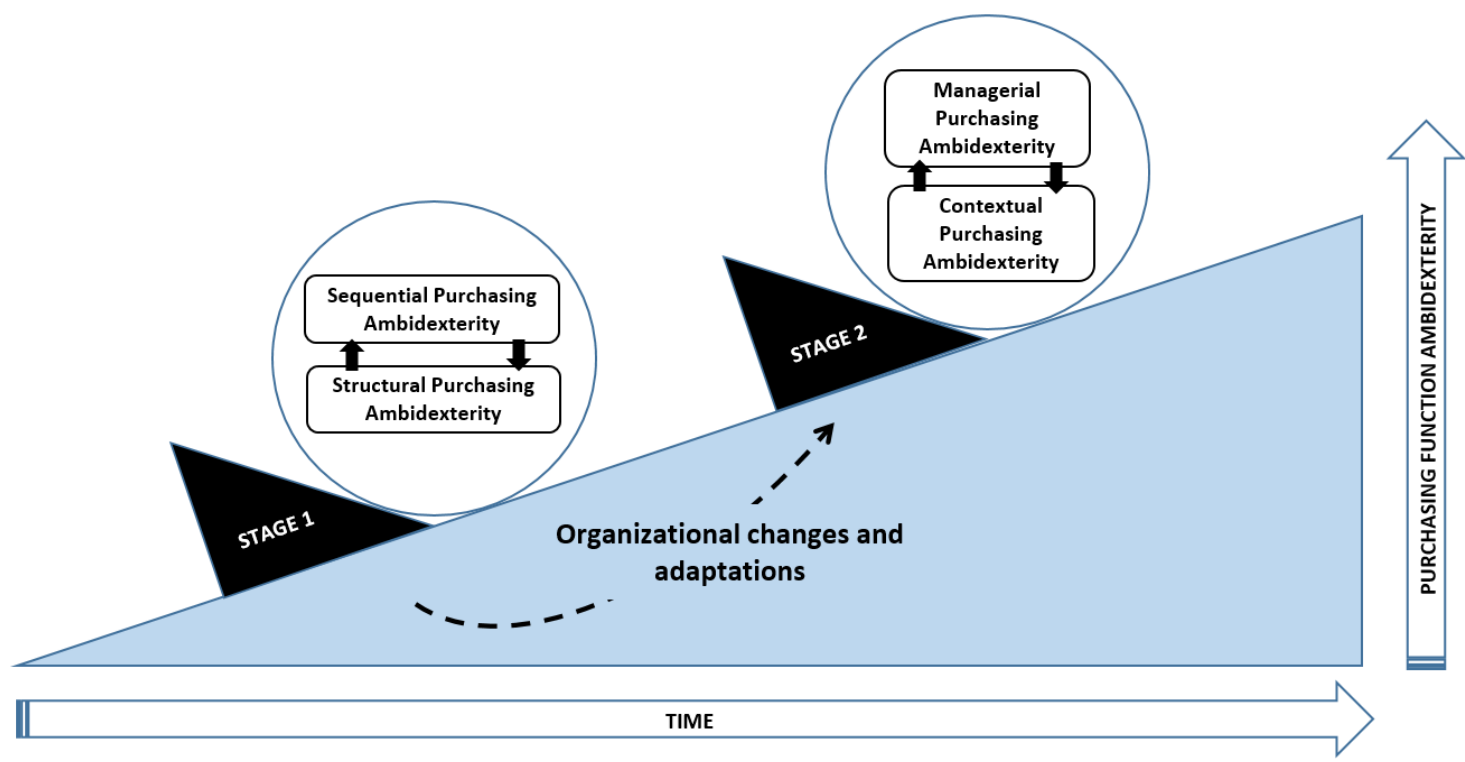

Fig 3: Complementarities between four types of ambidexterity and the two-stage implementation of purchasing ambidexterity at S Corp (Source: Authors).

\subsection{Refined conceptual framework}

Overall, our study indicates that all the four types of purchasing ambidexterity are manifested at S Corp, that tensions occur between exploration and exploitation, and that complementarities between different types of ambidexterity mitigate these tensions. At S Corp, the way these four types of ambidexterity are organized are key to enabling purchasing to contribute to the firm's innovations. In particular, structural and managerial ambidexterity appear to facilitate the right balance between exploration and exploitation by reducing tensions.

Considering these findings, we refined our initial conceptual framework (fig 4). The first change is related to the manifestations of the different types of purchasing ambidexterity. The answer provided to RQ1 allows us to populate the main characteristics of each type of purchasing ambidexterity. The second change concerns the tensions: we observed typical tensions which occurred at S Corp, which are displayed in our refined framework. Finally, the third change is about the complementarities we observed. The two stages described above are now part of the new framework, as a longitudinal view of the development of purchasing ambidexterity. Purchasing ambidexterity is formed as the result of this process that combine these four dimensions over time. 


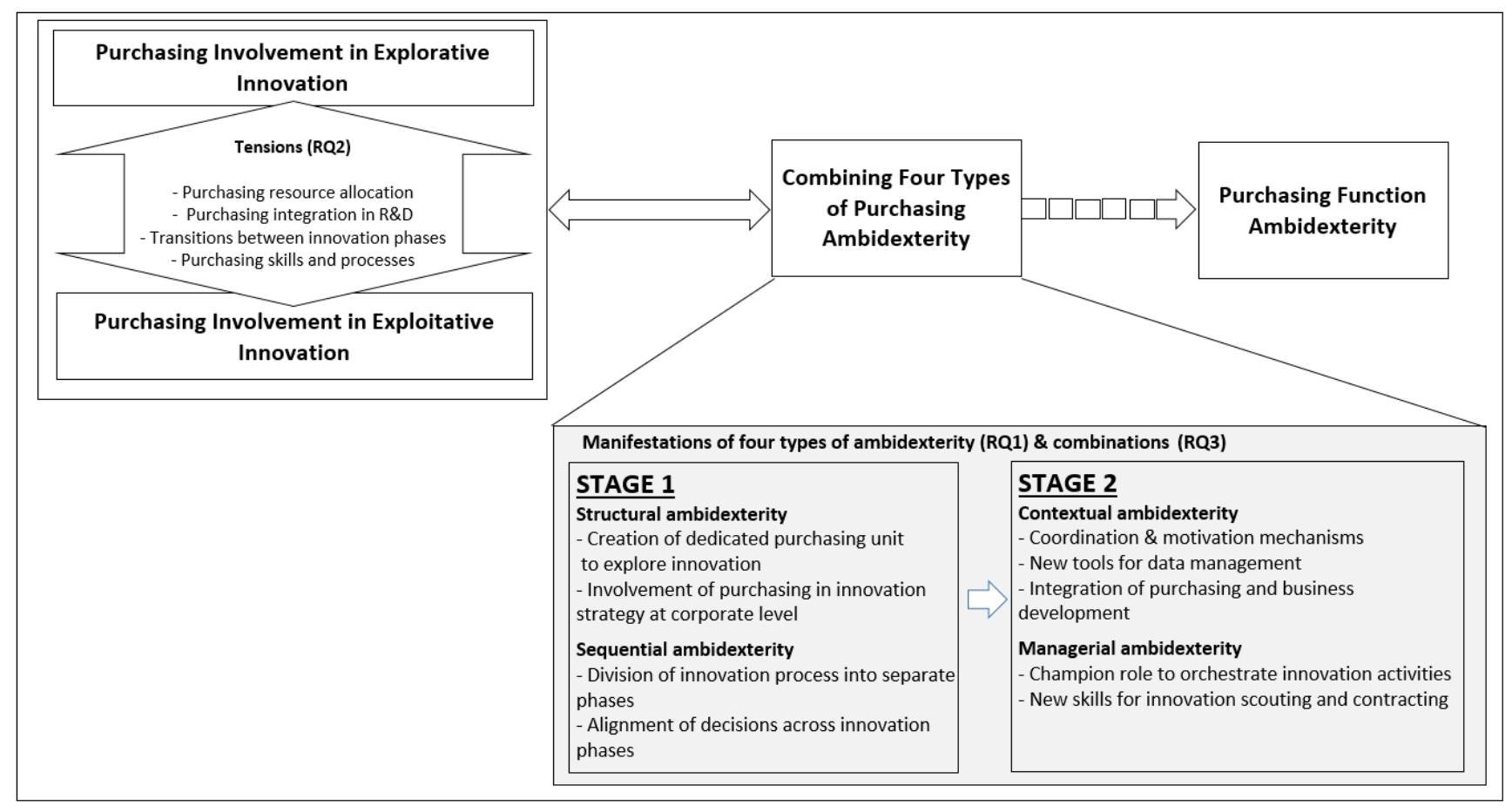

Figure 4: Refined conceptual framework (Source: Authors)

\section{Conclusion}

We have investigated how purchasing contributes to exploitative and exploratory innovation by developing an ambidextrous purchasing function. We have observed how $\mathrm{S}$ Corp, a large multi-national firm with exemplar practices in purchasing, has successfully implemented four types of purchasing ambidexterity (structural, sequential, contextual and managerial ambidexterity). We have reported on complementarities between the types of purchasing ambidexterity and how these help to resolve the tensions that arise from having balance exploratory and exploitative innovation activities.

\section{Theoretical implications}

Our article investigates the concept of organizational ambidexterity in the context of purchasing. Previous research has shown how purchasing can contribute to innovation, including dual roles of purchasing (Schiele, 2010), and various organizational options (Luzzini et al., 2011; Mikkelsen and Johnsen, 2018). We contribute to this stream of research in several ways.

First, we suggest that purchasing ambidexterity can facilitate the purchasing function's contribution to innovation and we demonstrate how this is instrumental to purchasing's ability to balance exploitative and exploratory innovation. We suggest that purchasing can be at the heart of an ecosystem to manage these two contradictory activities (Gualandris et al., 2018). Our findings show how purchasing ambidexterity can help to ease tensions, which occur when purchasing contributes both to explorative and exploitative innovation.

Second, we elucidate different types of purchasing ambidexterity. We show how structural purchasing ambidexterity at the organizational level facilitates purchasing contribution to innovation through the creation of a differentiated and autonomous unit to manage exploratory innovations. The effectiveness of structural differentiation has been argued elsewhere (Boumgarden et al., 2012; Raisch et al 2009); we elaborate the 
field of ambidexterity in a purchasing context by shedding light on how purchasing can redesign its organization through the addition of a distinct and autonomous unit dedicated to innovation exploration. We propose the concept of managerial purchasing ambidexterity especially through the purchasing champion role, highlighting its role in orchestrating the balance between exploratory and exploitative innovations.

Third, our study shows how an ambidextrous purchasing organization depends on combinations and strong links with the rest of the firm to reach a balance in execution, including a strong internal network. Linkages between a purchasing unit dedicated to exploratory innovation and the rest of the firm are ensured by a set of routines and directives, and enhanced by resource sharing, coordination and control (Boumgarden et al, 2012). We suggest that structural differentiation enables purchasing's contribution to exploration but requires strong complementarities with other types of ambidexterity. Furthermore, managerial ambidexterity may be effective in combination with contextual ambidexterity to facilitate structural and sequential ambidexterity. Combining managerial ambidexterity and contextual ambidexterity at the individual level can help to increase the chance of success in structural and sequential ambidexterity within the purchasing function. We suggest that managerial ambidexterity is not only dependent on managerial capabilities but also needs to be considered together with other types of ambidexterity: contextual and managerial ambidexterity, i.e. individual levels, support sequential and structural ambidexterity, i.e. organizational level.

Finally, we have proposed that purchasing ambidexterity develops over time in two distinct stages. We suggest that the first stage of purchasing ambidexterity emerges through the implementation of structural and sequential ambidexterity. Then, as purchasing ambidexterity gains a higher level of maturity in the second stage, the firm can consolidate its processes and skills by implementing contextual and managerial ambidexterity.

\section{Managerial implications}

In any organization, the alignment of decisions and the transitions across innovation phases are critically sensitive and must be managed with strong coordination mechanisms and structured processes. The purchasing function should also be adapted: developing purchasing ambidexterity is part of this adaptation. Our findings provide several insights for managers on how to facilitate purchasing contribution to innovation through ambidexterity. First, our suggestion to practitioners is to consider changing the purchasing operating model: involving purchasing in innovation is a company-wide strategic transformation to create a competitive advantage to the firm. Second, having to manage both exploratory and exploitative innovations inevitably causes tensions: our study may help practitioners intending to shape, adapt or redesign their purchasing organizations to better balance these fundamentally opposing tasks. We would encourage practitioners to modify their purchasing organization by setting up a specific unit to contribute to exploratory innovation and spreading incentives so that purchasing is better motivated to contribute to innovation. They should also consider purchasing integration with other departments, such as business development, as well as the creation of a skilled champion roles to contribute to the innovation process.

\section{Limitations and future avenues of research}

Relying on a single case study has obvious limitations but empirical generalization was not our objective. Instead, our intention was to investigate an exemplar of purchasing ambidexterity to elaborate on the concept of purchasing ambidexterity and we hope others will draw inspiration from this. 
We suggest further research to follow up on our findings. Further research could investigate who ends up taking responsibility for managing the tensions between exploration and exploitation, for example, we need further insights into managerial purchasing ambidexterity such as the creation of champion roles. Also, future research could investigate the diachronic vision of the way that the four types of ambidexterity are embedded over time, through the use of additional case studies and longitudinal studies.

\section{References}

Adler, P. S., Benner, M., Brunner, D. J., MacDuffie, J. P., Osono, E., Staats, B. R. \& Winter, S. G. (2009). Perspectives on the productivity dilemma. Journal of Operations Management, 27(2), 99-113.

Ahuja, G., \& Morris Lampert, C. (2001). Entrepreneurship in the large corporation: A longitudinal study of how established firms create breakthrough inventions. Strategic Management Journal, 22(6-7), 521-543.

Andriopoulos, C., \& Lewis, M. W. (2009). Exploitation-exploration tensions and organizational ambidexterity: Managing paradoxes of innovation. Organization Science, 20(4), 696-717.

Andriopoulos, C., \& Lewis, M. W. (2010). Managing innovation paradoxes: Ambidexterity lessons from leading product design companies. Long Range Planning, 43(1), 104-122.

Atuahene-Gima, K. (1995). An exploratory analysis of the impact of market orientation on new product performance: a contingency approach. Journal of Product Innovation Management, 12(4), 275-293.

Atuahene-Gima, K. (2005). Resolving the capability-rigidity paradox in new product innovation. Journal of Marketing, 69(4), 61-83.

Araujo, L., Dubois, A. \& Gadde, L.-E. (1999). Managing interfaces with suppliers, Industrial Marketing Management, 28 (5), 497-506.

Barratt, M., Choi, T. Y., \& Li, M. (2011). Qualitative case studies in operations management: Trends, research outcomes, and future research implications. Journal of Operations Management, 29(4), 329-342.

Benner, M. J., \& Tushman, M. L. (2003). Exploitation, exploration, and process management: The productivity dilemma revisited. Academy of Management Review, 28(2), 238-256.

Birkinshaw, J., \& Gupta, K. (2013). Clarifying the distinctive contribution of ambidexterity to the field of organization studies. The Academy of Management Perspectives, 27(4), 287-298.

Blome C, Schoenherr, \& T., Kaesser; M. (2013). Ambidextrous Governance in Supply Chains: The Impact on Innovation and Cost Performance, Journal of Supply Chain Management, 49 (4), 59-80

Bonesso, S., Gerli, F., \& Scapolan, A. (2014). The individual side of ambidexterity: Do individuals' perceptions match actual behaviors in reconciling the exploration and exploitation trade-off? European Management Journal, 32(3), 392-405.

Boumgarden, P., Nickerson, \& J., Zenger, T. R. (2012). Sailing into the wind: Exploring the relationships among ambidexterity, vacillation, and organizational performance. Strategic Management Journal, 33(6), 587-610.

Bower, J. L., \& Christensen, C. M. (1996). Disruptive technologies: Catching the wave. The Journal of Product Innovation Management, 1(13), 75-76.

Brion, S., Favre-Bonté, V., \& Mothe, C. (2008). Quelles formes d'ambidextrie pour combiner innovations d'exploitation et d'exploration? Management International, 12(3), 29. 
Brown, S. L., \& Eisenhardt, K. M. (1997). The art of continuous change: Linking complexity theory and time-paced evolution in relentlessly shifting organizations. Administrative Science Quarterly, 42, 1-34.

Cao, Q., Gedajlovic, E., \& Zhang, H. (2009). Unpacking organizational ambidexterity: Dimensions, contingencies, and synergistic effects. Organization Science, 20(4), 781-796.

Cantarello, S., Martini, A., \& Nosella, A. (2012). A multi-level model for organizational ambidexterity in the search phase of the innovation process. Creativity and Innovation Management, 21(1), 28-48.

Chanal, V., \& Mothe, C. (2005). Concilier innovations d'exploitation et d'exploration. Revue Française de Gestion, (1), 173-191.

Christensen, C. M., (1997). The Innovator's Dilemma: The Revolutionary Book that Will Change the Way You Do Business. Collins Business Essentials.

DeCuir-Gunby, J. T., Marshall, P. L., \& McCulloch, A. W. (2011). Developing and using a codebook for the analysis of interview data: An example from a professional development research project. Field Methods, 23(2), 136-155.

Dougherty, D., \& Hardy, C. (1996). Sustained product innovation in large, mature organizations: Overcoming innovation-to-organization problems. Academy of Management Journal, 39(5), 1120-1153.

Dubois, A., \& Araujo, L. (2007). Case research in purchasing and supply management: opportunities and challenges. Journal of Purchasing and Supply Management, 13(3), 170-181.

Duncan, R. (1976). The ambidextrous organization: Designing dual structures for innovation. In R. H. Kilmann, L. R. Pondy, D. Slevin (Eds.), The Management of Organization Design (167188). New York: North Holland.

Easterby-Smith, M., Thorpe, \& R. Lowe, A. (1991), Introduction to Management Research, Sage, London.

Eriksson, P. E. (2013). Exploration and exploitation in project-based organizations: Development and diffusion of knowledge at different organizational levels in construction companies. International Journal of Project Management, 31(3), 333-341.

Esfahbodi, A., Zhang, Y., \& Watson, G. (2016). Sustainable supply chain management in emerging economies: Trade-offs between environmental and cost performance. International Journal of Production Economics, 181, 350-366.

Flyvbjerg, B. (2006). Five misunderstandings about case-study research. Qualitative Inquiry, 12 (2), 219-245.

Gadde, L. E., \& Wynstra, F. (2017). Purchasing and supply management: on strategic roles and supplier interfaces. In No Business is an Island: Making Sense of the Interactive Business World, 67-86. Emerald Publishing Limited.

Gibson, C. B., Birkinshaw, J., 2004. The antecedents, consequences and mediating role of organizational ambidexterity. Academy of Management Journal, 47, 209-226.

Giunipero, L. C., \& Pearcy, D. H. (2000). World- class purchasing skills: an empirical investigation. Journal of Supply Chain Management, 36(3), 4-13.

Gonzalez-Zapatero, C., Gonzalez-Benito, J., \& Lannelongue, G. (2017). Understanding how the functional integration of purchasing and marketing accelerates new product development. International Journal of Production Economics, 193, 770-780.

Groysberg, B., \& Lee, L. E. (2009). Hiring stars and their colleagues: Exploration and exploitation in professional service firms. Organization Science, 20(4), 740-758.

Gualandris, J., Legenvre, H., \& Kalchschmidt, M. (2018). Exploration and exploitation within supply networks: Examining purchasing ambidexterity and its multiple performance implications. International Journal of Operations \& Production Management, 38(3), 667-689 
Guba, E. G., \& Lincoln, Y. S. (2005). Paradigmatic Controversies, Contradictions, and Emerging Confluences. In N. K. Denzin \& Y. S. Lincoln (Eds.), The Sage handbook of qualitative research (pp. 191-215). Thousand Oaks, CA, Sage Publications Ltd.

Gupta, A. K., Smith, K. G., \& Shalley, C. E. (2006). The interplay between exploration and exploitation. Academy of Management Journal, 49(4), 693-706.

Gupta, A. K., \& Govindarajan, V. (2000). Knowledge flows within multinational corporations. Strategic Management Journal, 473-496.

Halinen, A., \& Törnroos, J.Å. (2005), Using case methods in the study of contemporary business networks", Journal of Business Research, 58 (9), 1285-1297.

He, Z. L., \& Wong, P. K. (2004). Exploration vs. exploitation: An empirical test of the ambidexterity hypothesis. Organization Science, 15, 481-494.

Holstein, J. A., \& Gubrium, J. F. (2004). The active interview. Qualitative Research: Theory, Method and Practice, 2, 140-161.

Homfeldt, F., Rese, A., Brenner, H., Baier, D., \& Schäfer, T. F. (2017). "Identification and Generation of Innovative Ideas in the Procurement of the Automotive Industry: The Case of AUDI AG”. International Journal of Innovation Management, 21(07), 1750053.

Jansen, J. J., Van Den Bosch, F. A., \& Volberda, H. W. (2006). Exploratory innovation, exploitative innovation, and performance: Effects of organizational antecedents and environmental moderators. Management Science, 52(11), 1661-1674.

Jansen, J. J., Tempelaar, M. P., Van den Bosch, F. A., \& Volberda, H. W. (2009). Structural differentiation and ambidexterity: The mediating role of integration mechanisms. Organization Science, 20(4), 797-811.

Järvensivu, T., \& Törnroos, J. Å. (2010). Case study research with moderate constructionism: Conceptualization and practical illustration. Industrial Marketing Management, 39(1), 100-108.

Johnsen, T. E. (2009). Supplier involvement in new product development and innovation: Taking stock and looking to the future. Journal of Purchasing and Supply Management, 15(3), 187-197.

Ketokivi, M., \& Choi, T. (2014). Renaissance of case research as a scientific method. Journal of Operations Management, 32(5), 232-240.

Kristal, M.M., Huang, X., \& Roth, A.V. (2010). The effect of an ambidextrous supply chain strategy on combinative competitive capabilities and business performance. Journal of Operations Management 28, 415-429.

Lavie, D., \& Rosenkopf, L. (2006). Balancing exploration and exploitation in alliance formation. Academy of Management Journal, 49(4), 797-818.

Lavie, D., Stettner, U., \& Tushman, M. (2010). Exploration and exploitation within and across organizations. Academy of Management Annals, 4, 109-155.

Lawrence, P. R., \& Lorsch, J. W. (1967). Differentiation and integration in complex organizations. Administrative Science Quarterly, 12, 1-47.

Leonard-Barton, D. (1992). Core capabilities and core rigidities: A paradox in managing new product development. Strategic Management Journal, 13(1), 111-125.

Levinthal, D. A., \& March, J. G. (1993). The myopia of learning. Strategic Management Journal, 14(2), 95-112.

Linder, J. C., Jarvenpaa, S., \& Davenport, T. H. (2003). Toward an innovation sourcing strategy. MIT Sloan Management Review, 44(4), 43.

Luzzini, D., \& Ronchi, S. (2011). Organizing the purchasing department for innovation. Operations Management Research, 4(1-2), 14-27.

Maier, M. Rüc, \& P, Brem, A. (2017). How to Integrate Suppliers into the Innovation Process? An Explorative Case of Champion Formalization in the Purchasing Department in Times of Open Innovation. International Journal of Innovation and Technology Management, 14(06). 
March, J. G. (1991). Exploration and exploitation in organizational learning. Organization Science, 2, 71-87.

Melander, L., \& Lakemond, N., (2014). Variation of purchasing's involvement: case studies of supplier collaborations in new product development. International Journal of Procurement Management, 7(1), 103-118.

Mikkelsen, O. S., \& Johnsen, T. E. (2018). Purchasing involvement in technologically uncertain new product development projects: Challenges and implications. Journal of Purchasing and Supply Management, 25 (3).

Miles, M. B., Huberman, A. M., Huberman, M. A., \& Huberman, M. (1994). Qualitative data analysis: An expanded sourcebook. Sage.

Mom, T. J., Van Den Bosch, F. A., \& Volberda, H. W. (2009). Understanding variation in managers' ambidexterity: Investigating direct and interaction effects of formal structural and personal coordination mechanisms. Organization Science, 20(4), 812-828.

Monczka, R. M., Handfield, R. B., Giunipero, L. C., \& Patterson, J. L. (2015). Purchasing and supply chain management. Cengage Learning.

Narasimhan, R., \& Narayanan, S. (2013). Perspectives on supply network-enabled innovations. Journal of Supply Chain Management, 49(4), 27-42.

Nerkar, A. (2003). Old is gold? The value of temporal exploration in the creation of new knowledge. Management Science, 49(2), 211-229.

Nerkar, A., Roberts, P. W., 2004. Technological and product-market experience and the success of new product introductions in the pharmaceutical industry. Strategic Management Journal, 25(8-9), 779-799.

Nickerson, J. A., \& Zenger, T. R. (2002). Being efficiently fickle: A dynamic theory of organizational choice. Organization Science, 13(5), 547-566.

O'Connor, G. C., \& Rice, M. P. (2013). A comprehensive model of uncertainty associated with radical innovation. Journal of Product Innovation Management, 30, 2-18.

O'Reilly III, C. A., \& Tushman, M. L. (2004). The ambidextrous organization. Harvard Business Review, 82(4), 74.

O'Reilly III, C. A., \& Tushman, M. L. (2011). Organizational ambidexterity in action: How managers explore and exploit. California Management Review, 53(4), 5-22.

O'Reilly III, C. A., \& Tushman, M. L. (2013). Organizational ambidexterity: Past, present, and future. The Academy of Management Perspectives, 27(4), 324-338.

Oosterhuis, M., Molleman, E., van der Vaart, T., 2005. Multilevel issues in supply chain management. Research Methodologies in Supply Chain Management, 283-297.

Pagell, Mark, \& Zhaohui Wu. (2009). Building a more complete theory of sustainable supply chain management using case studies of 10 exemplars. Journal of supply chain management 45.2 37-56.

Patrucco, A. S., Luzzini, D., \& Ronchi, S. (2017). Achieving innovation through supplier collaboration: the role of the purchasing interface. Business Process Management Journal, 23(6), 1270-1289.

Pettigrew, A. M. (1992). The character and significance of strategy process research. Strategic Management Journal, 13(2), 5-16.

Prahalad, C. K., \& Bettis, R. A. (1986). The dominant logic: A new linkage between diversity and performance. Strategic Management Journal, 7(6), 485-501.

Ragin, C.C. (1992). In: Ragin, C.C., Becker, H.S. (Eds.), "Casing”, and the Process of Social Inquiry. In What is a Case? Exploring the Foundations of Social Inquiry. Cambridge University Press, Cambridge, 217-226.

Raisch, S., \& Birkinshaw, J., (2008). Organizational ambidexterity: Antecedents, outcomes, and moderators. Journal of Management, 34(3), 375-409. 
Raisch, S., Birkinshaw, J., Probst, G., \& Tushman, M. L., (2009). Organizational ambidexterity: Balancing exploitation and exploration for sustained performance. Organization Science, 20(4), 685-695.

Rosenkopf, L., \& Nerkar, A., (2001). Beyond local search: boundary-spanning, exploration, and impact in the optical disk industry. Strategic Management Journal, 22(4), 287-306.

Rogan, M., \& Mors, M. L. (2014). A network perspective on individual-level ambidexterity in organizations. Organization Science, 25(6), 1860-1877.

Rothaermel, F. T., \& Alexandre, M. T., (2009). Ambidexterity in technology sourcing: The moderating role of absorptive capacity. Organization Science, 20(4), 759-780.

Rothaermel, F. T., \& Deeds, D. L., (2004). Exploration and exploitation alliances in biotechnology: A system of new product development. Strategic Management Journal, 25(3), 201-221.

Schiele, H. (2010). Early supplier integration: the dual role of purchasing in new product development. R\&d Management, 40(2), 138-153.

Schoenherr, T., Modi, S. B., Benton, W. C., Carter, C. R., Choi, T. Y., Larson, P. D., \& Wagner, S. M. (2012). Research opportunities in purchasing and supply management. International Journal of Production Research, 50(16), 4556-4579.

Servajean-Hilst, R., \& Calvi, R. (2018). Shades of the Innovation-Purchasing Function-The Missing Link of Open Innovation. International Journal of Innovation Management, 22(01), 1850008.

Siggelkow, N., \& Levinthal, D. A., (2003). Temporarily divide to conquer: Centralized, decentralized, and reintegrated organizational approaches to exploration and adaptation. Organization Science, 14(6), 650-669.

Slater, S. F., Mohr, J. J., \& Sengupta, S., (2014). Radical product innovation capability: Literature review, synthesis, and illustrative research propositions. Journal of Product Innovation Management, 31(3), 552-566.

Smith, W. K., \& Tushman, M. L., (2005). Managing strategic contradictions: A top management model for managing innovation streams. Organization Science, 16(5), 522-536.

Spina, G., Caniato, F., Luzzini, D., \& Ronchi, S., (2013). Past, present and future trends of purchasing and supply management: An extensive literature review. Industrial Marketing Management, 42(8), 1202-1212.

Swink, M., \& Schoenherr, T. (2015). The effects of cross-functional integration on profitability, process efficiency, and asset productivity. Journal of Business Logistics, 36(1), 69-87.

Taylor, A., \& Helfat, C. E. (2009). Organizational linkages for surviving technological change: Complementary assets, middle management, and ambidexterity. Organization Science, 20(4), 718-739.

Tripsas, M., \& Gavetti, G. (2000). Capabilities, cognition, and inertia: Evidence from digital imaging. Strategic Management Journal, 21(10-11), 1147-1161.

Turner, N., Swart, J., \& Maylor, H. (2013). Mechanisms for managing ambidexterity: A review and research agenda. International Journal of Management Reviews, 15(3), 317-332.

Tushman, M. L., \& O'Reilly, C. A. (1997). Winning through innovation: A practical guide to managing organizational change and renewal. Cambridge, MA: Harvard Business School Press.

Tushman, M. L., \& O'Reilly, C. A. (1996). The ambidextrous organizations: Managing evolutionary and revolutionary change. California Management Review, 38(4), 8-30

Van Echtelt, F. E., Wynstra, F., Van Weele, A. J., \& Duysters, G. (2008). Managing supplier involvement in new product development: a multiple-case study. Journal of Product Innovation Management, 25(2), 180-201.

Weber, R. P. (1990). Basic content analysis (No. 49). Sage. 
Wynstra, F., Weggeman, M., \& Van Weele, A. (2003). Exploring purchasing integration in product development. Industrial Marketing Management, 32(1), 69-83.

Appendix 1: Interview guide for Purchasing function

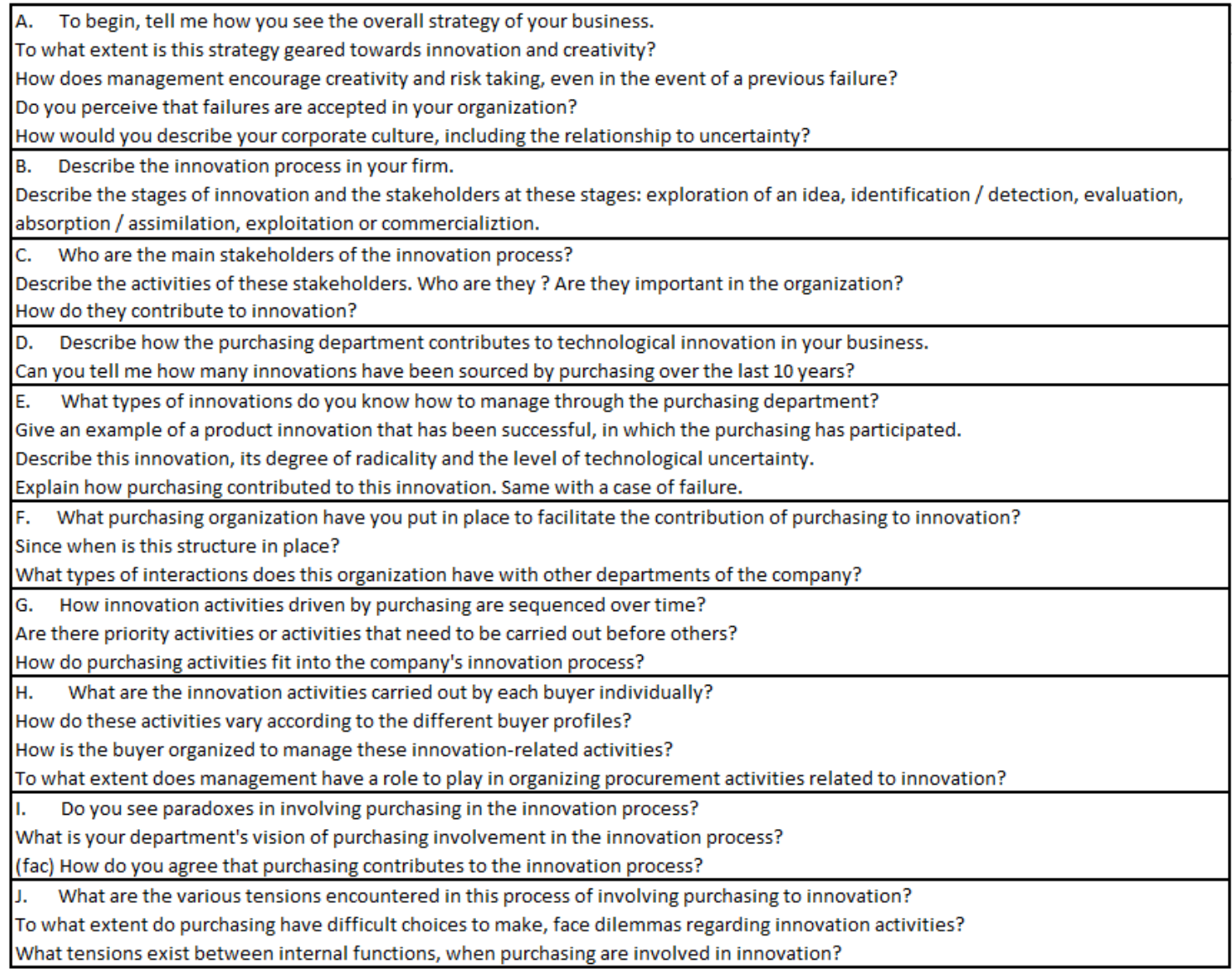

